\title{
A JOINT TRAVEL DEMAND AND ENVIRONMENTAL MODEL TO INCORPORATE EMISSION PRICING FOR LARGE TRANSPORTATION NETWORKS
}

By

Sabyasachee Mishra, Ph.D., P.E.

Research Assistant Professor

National Center for Smart Growth Research and Education

University of Maryland

College Park, MD 20742

Phone: (301) 405-9424

Email: mishra@umd.edu

Timothy F. Welch, JD, LL.B

PhD Research Assistant

National Center for Smart Growth Research and Education

University of Maryland

College Park, MD 20742

Phone: (301) 405-4481

Email: twelch@umd.edu

Total Word Count: Words (5994) + Number of Tables and Figures (6x250) =7,494 Date Submitted: March 9, 2012

Revised Paper Submitted for Publication in Transportation Research Record 


\begin{abstract}
Emission reduction strategies are gaining greater attention to support the national objective for a sustainable and green transportation system. A large percent of emission contribution that arises from transportation modes are primarily from auto and truck travel. Reductions in highway travel require prudent planning strategies and modeling user's response to planner's policies. Modeling planning goals and user's response is a challenging task. In this paper the authors present a joint travel demand and environmental model to incorporate vehicle emission pricing (VEP) as a strategy for emission reduction. First, the travel demand model determines the destination, mode and route choice of the users in response to the VEP strategy set by the planner. Second, the emission model provides $\mathrm{NOx}, \mathrm{VOC}$, and $\mathrm{CO}_{2}$ estimates at a very detailed level. A Base-case and three models are proposed to incorporate VEP in a multimodal transportation network. The objective function of the Base-case is the minimization of Total System Travel Time (TST), and the models are designed with the objective of minimizing Total System Emission (TSE). User Equilibrium method is used for travel to model user responses and solved by Frank Wolfe algorithm. The Base-case represents “do-nothing” conditions and the three models address the interactions between planner's perspectives and user responses to VEP strategies. The proposed model is applied to Montgomery County's (located in the Washington DC-Baltimore region) multimodal transportation network. The case study results show that VEP can be used as a tool for emission reduction in transportation planning and policy.
\end{abstract}

Key Words: Emission pricing, travel demand, multimodal, user equilibrium, frank wolfe

\title{
INTRODUCTION
}

In the United States, autos and trucks generate 25 percent of $\mathrm{CO}_{2}$ emissions and account for over 70 percent of the country's petroleum consumption (1). It is a surmountable task to achieve reductions in greenhouse gases and ozone creating compounds to sustainable levels. Federal and state agencies aim to minimize the harmful effects of transportation on the environment to achieve greenhouse gas and ozone targets. In particular, an explicit consideration is given to reducing levels of $\mathrm{NO}_{\mathrm{x}}$ and $\mathrm{VOC}$, which can contribute to ozone creation, and $\mathrm{CO}_{2}$ (greenhouse gas) through better operational level planning. Measuring and reducing emissions requires quantification in modeling activities and incorporation into planning methods. The choice of type and nature of emission functions are important for deriving accurate estimates in the planning of transportation activities. Currently, there are two types of feasible methods, one is a long-term solution to improve public transport such that the mode shift can cause a large emission reduction and the other is a short-term solution to influence traveler behavior by imposing vehicle emission pricing (VEP) such that there are minimal emissions produced in the system (2). Although the former is the ideal scenario, for a long-term sustainable solution, the latter needs more careful analysis before determining additional cost to the user to achieve substantive 
emission reductions. In both cases there is a need for the development of travel demand or behavioral models. Such models are capable of examining the travel behavior of road users and their responses to impedances such as VEP to achieve emission reductions. In this context, VEP can be used as a tool to model traffic flows in a transportation system, by choosing an alternate route, being elastic to travel options or a combination of both.

In this paper, we propose a joint travel demand (called a demand model, hereafter) and emission model to achieve emission reduction for the major pollutants $\mathrm{NO}_{\mathrm{x}}, \mathrm{VOC}$, and $\mathrm{CO}_{2}$. The demand model incorporates individual travel behavior in determining travel choice and route choice in response to emission pricing strategies set by the decision maker. The Environmental Protection Agency (EPA) developed MOtor Vehicle Emission Simulator (MOVES), is integrated with the demand model for estimation of pollutants. Developing such models is complex and involves two major hurdles. First, the difficulty lies in obtaining specific and accurate emission levels with which to model individual driver responses to examine how the targets are achieved. Second, the application of these models in real world case studies to assist federal, state and local agencies (or decision makers) to achieve emission reduction objectives.

The proposed methodology in the paper incorporates a VEP technique in a step by step manner. In the next section a literature review is presented, followed by model formulation and solution methodology. The case study section describes the overview of the region's geography, and transportation network characteristics. Model application and scenario results are presented in the next section. Finally, the conclusion section summarizes the findings, depicts contributions of the paper and enumerates future scope of research.

\section{LITERATURE REVIEW}

Emission reduction strategies are well studied in the literature. In a decision making framework these strategies can be viewed as a Stackelberg's game theory in bi-level modeling. The upper level represents the decision maker's goal (or preference) based on a certain objective and the lower level represents user's response (whether or not to follow) the upper level strategy. In transportation engineering, the upper level can be considered as the minimization of emission through VEP and the lower level represents driver's response to the policy at the upper level (3)(4). In some cases the upper level strategies are a prioi, and exogenously defined and in others the strategies are concurrently optimized in conjunction with the lower level. The lower level is solved with the traffic assignment optimization problem, and the most common objectives are the minimization of cost and time (5). Although in reality the two objectives (minimization of cost and time) in the lower level, are nearly identical, cost is considered a separate variable in order to achieve positive externalities like revenue generation or market based trip decision making. Uncommon in the literature is the objective to minimize the environmental impacts of vehicular traffic through a pricing mechanism (or derivatives thereof). 
A number of studies have developed emission factors before applying them in the assignment process. While factors may vary based on area type, speed, highway congestion, weather conditions and other factors, use of these factors require a large amount of effort in data collection. In addition, development of emissions factors requires a calibration process and may not lead to an accurate estimation of emissions. The EPA MOVES model has been extensively developed to measure emission factors for different regions in the U.S. While some researchers point out a few limitations in models like MOVES (6), where there is a specialized need for emissions modeling, for the purpose of this research design and other scenario-based research, MOVES provides an excellent tool to measure changes in emissions based on changes in traffic demand, assignment and other network characteristics.

Several studies examine the relationship between network flow and system emissions (3)(7). Effective modeling efforts have focused on incorporating road pricing into the highway assignment algorithm via Waldrop's User Equilibrium (UE) objective function and a Frank-Wolf (FW) solution approach (3). The results typically show that flow, as a function of link volume and capacity, has a substantial impact on the overall level of emissions. However this is not the only condition that potentially affects total emissions. Nagurney (7) points out several conditions which can produce increased network emissions which include (somewhat paradoxically) the addition of a link, a decrease in travel demand and improvements in link cost structure (i.e. travel on the link becomes cost effective). The results of the study point out that a reduction in emissions requires not only improvements to network flow, possibly through supply-side management (8)(9), but also with the addition of demand management, most feasibly in the form of a VEP.

The most efficient and equitable method to achieve substantive reductions in vehicle emissions is through a pricing mechanism ((10), (11)). Previous studies show that pricing can have substantial impacts depending on the policy objective, particularly in terms of internalizing the negative effects of emissions and for the market effect of pricing on trip, mode and route choice (12). An effective emission pricing strategy requires a large enough network to provide alternative routes and links with low enough saturation to absorb additional volume in order to show significant emissions improvement (13). An effective pricing strategy is therefore one that either prices links in a given area (such a non-attainment area) or along a single corridor. On the other hand, in the absence of viable route and link alternatives a mix of pricing and demand elasticity, which is the assumption that at the right price some trips will not occur or travelers will switch modes, can be used to effectively reduce TSE ((4),(12), (14), (15)).

Therefore the application of VEP strategy should be incorporated for emission minimization to examine the interaction between decision maker's policy and the user's response. Application of VEP strategies for real world conditions is limited in the literature. This paper analyzes a Base-case depicting existing emission levels, and proposes a set of models to minimize emissions in a combined framework of user's response to decision maker's policies. The framework consists of a joint travel demand and emission model to incorporate VEP 
strategies for emission minimization. In the remainder of the paper the terms emission pricing and VEP are used interchangeably. The next section describes the model formulation. The notations for model formulation are presented below.

\begin{tabular}{|c|c|c|}
\hline Notation & & Explanation \\
\hline$\hat{d}_{i j}^{\varphi}$ & : & Potential demand between $i-j$ \\
\hline$\Phi_{a}$ & : & Emissions cap for each link $a$ \\
\hline$A O C_{m}^{p}$ & : & Auto operating cost for mode $m$ and purpose $p$ \\
\hline$C_{a}$ & : & The capacity for link $a$ \\
\hline$C_{j n}$ & : & Correction term to compensate for sampling error in model estimation \\
\hline$D A_{m}^{p}$ & : & Drive access time for mode $m$ and purpose $p$ \\
\hline$D_{i j}^{-1}$ & : & The inverse demand function associated with O-D pair $i-j$ \\
\hline$D_{i j}^{k}$ & : & Various distance terms (linear, log, squared, cubed and square root) \\
\hline$E_{j}^{k}$ & : & Employment of type $k$ in zone $\mathrm{j}$ \\
\hline$I V T T_{m}^{p}$ & : & In-vehicle travel time for mode $m$ and purpose $p$ \\
\hline$I W T a 1_{m}^{p}$ & : & Initial waiting time less than 7.5 minutes for mode $m$ and purpose $p$ \\
\hline$I W T b_{m}^{p}$ & : & Initial waiting time greater than 7.5 minutes for mode $m$ and purpose $p$ \\
\hline$L_{i j}$ & : & The mode choice logsum between zone pair $i j$ \\
\hline$N O T_{m}^{p}$ & : & Number of transfers for mode $m$ and purpose $p$ \\
\hline$N_{n}^{k}$ & : & Person, household or production zone characteristics for trip $n$ \\
\hline$P C_{m}^{p}$ & : & Parking cost for mode $m$ and purpose $p$ \\
\hline$S_{j}$ & : & Size variable for destination zone $j$ \\
\hline$T E T_{m}^{p}$ & : & Terminal time for mode $m$ and purpose $p$ \\
\hline$T F_{m}^{p}$ & : & Transit fare for mode $m$ and purpose $p$ \\
\hline$U_{i j n}$ & : & $\begin{array}{l}\text { The utility of choosing a trip attraction destination } j \text { for a trip } n \text { produced in } \\
\text { zone } i\end{array}$ \\
\hline$U_{m}^{p}$ & : & Utility function for auto and transit travel \\
\hline$W T_{m}^{p}$ & : & Waiting time for mode $m$ and purpose $p$ \\
\hline$Z_{j}^{k}$ & : & Attraction zone characteristics \\
\hline$d_{i j}^{\varphi}\left(x_{i j}\right)$ & : & New demand between O-D pair $i-j$ \\
\hline$e_{a}$ & : & Emission price \\
\hline$e_{a}^{I}$ & : & Emission pricing for link in the corridor \\
\hline$e_{b}$ & : & Total corridor emission price \\
\hline$f_{i j}^{r}$ & : & Flow on path $r$, connecting each Origin-Destination (O-D) pair $(i-j)$ \\
\hline$l_{a}$ & : & Distance for link $a$ \\
\hline$l_{b}$ & : & Length of the corridor \\
\hline$q_{i j}$ & : & Demand between each Origin-Destination (O-D) pair $(i-j)$ \\
\hline$t_{a}$ & : & Travel time for link $a$ \\
\hline$t_{a}\left(x_{a}\right)$ & : & Travel cost on link $a$ as a function of flow \\
\hline$u_{a}$ & : & User cost for link $a$ \\
\hline $\begin{array}{l}u_{a}^{I}\left(x_{a}, e_{a}\right) \\
\quad u_{i j}^{c}\end{array}$ & $\begin{array}{l}: \\
:\end{array}$ & $\begin{array}{l}\text { Travel time function for Model- } 1 \text { which incorporates emission pricing term } e_{a} \\
\text { Least cost path between O-D pairs } i-j\end{array}$ \\
\hline$x_{a}$ & : & Flow for link $a$ \\
\hline$\alpha_{a}$ & : & Constant, varying by facility type (BPR function) \\
\hline
\end{tabular}




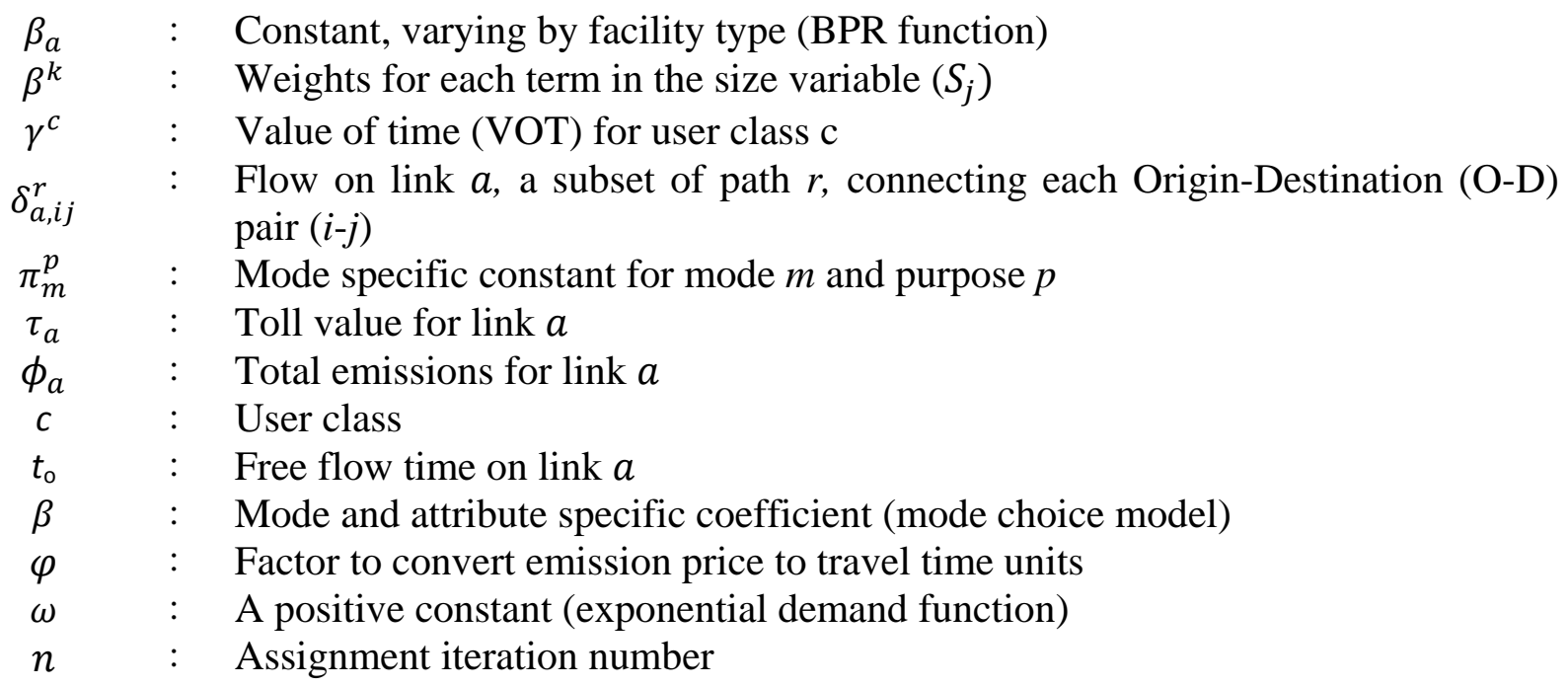

\section{MODEL FORMULATION}

In this section the Base-case (do-nothing) and three different models incorporating optimal emission pricing are presented. Each section describes the model formulation and the appropriate need for decision making.

\section{Base-Case}

The Base-case represents "do-nothing" or current conditions without any VEP. The user behavior is studied in the trip assignment stage and is solved by classical user equilibrium method (5).

$$
\text { Minimize } \sum_{a} \int_{0}^{x_{a}} t_{a}\left(x_{a}\right)
$$

subject to:

$$
\begin{gathered}
\sum_{r} f_{i j}^{r}=q_{i j} \\
x_{a}=\sum_{i} \sum_{j} \sum_{r} f_{i j}^{r} \delta_{a, i j}^{r} \\
f_{i j}^{r}, q_{i j}^{r} \geq 0
\end{gathered}
$$

The objective function shows minimization of TST of the network as per Wardrop's first principle, which denotes that "no user can experience a lower travel time by unilaterally changing routes” (16). In simple terms the equilibrium is achieved when the travel cost on all 
used paths is equal. The two terms in equation (1) represent the total travel cost. The first term, $t_{a}$, is the travel time for link $a$, which is a function of link flow $x_{a}$. Equation (2) is a flow conservation constraint to ensure that flow on all paths $r$, connecting each Origin-Destination (OD) pair $(i-j)$ is equal to the corresponding demand. In other words, all O-D trips must be assigned to the network. Equation (3) represents the definitional relationship of link flow from path flows. Equation (4) is a non-negativity constraint for flow and demand. The travel time function ta(.) is specific to a given link 'a' and the most widely used model is the Bureau of Public Roads (BPR) function given by

$$
t_{a}\left(x_{a}\right)=t_{o}\left(1+\alpha_{a}\left(\frac{x_{a}}{C_{a}}\right)\right)^{\beta_{a}}
$$

where $t_{o}($.$) is free flow time on link ' a$ ', and $\alpha_{a}$ and $\beta_{a}$ are constants (and vary by facility type). $C_{a}$ is the capacity for link $a$. In the base model the objective is minimization of total system travel time. Emission is not a component of the base case. The emission parameters are derived from MOVES and utilized exogenously to the assignment method for the Base-case.

When the objective function is expanded to include the minimization of TSE, the emission model is moved into the assignment program. After the initial iteration of assignment, based on free-flow travel time, the resulting emissions are calculated using the MOVES model derived emissions factors. The factors used are based on link speed, traffic volume, distance, time of day, facility type and area type. The pre-determined emissions cap is then subtracted from the newly calculated emissions which becomes the basis for the emissions charge at the end of each assignment iteration.

\section{Model-1: Link Based Emission Pricing}

When the decision maker has the objective to minimize total emission, link based emission pricing may be the first option. Based on a policy criteria such as links exceeding a threshold emission value need to be priced. The threshold value can be considered as an emission cap. The cap can be determined by calculating the link level emissions for the entire network in the base year by grams per mile for each link. The cap can then be set at the average of emissions per mile. The cap for each link is then determined by multiplying the average grams of emissions per mile by the distance of each link. The emissions cap for each link is:

$$
\Phi_{a}=\left[\frac{1}{N} \sum_{a=1}^{N}\left(\frac{\phi_{a}}{l_{a}}\right)\right] * l_{a}
$$

where $\phi_{a}$ is the total emissions for link $a$ calculated for each link in the base model and $l_{a}$ is the link distance. Once the cap is determined, the emission price $\left(e_{a}\right)$ can be incorporated into the travel demand model. The emission price can be converted to travel time units with 
appropriate factor $(\varphi)$ representing VOT in monetary terms. The revised user cost function for link based emission is

$$
u_{a}^{I}\left(x_{a}, e_{a}\right)=t_{a}\left(x_{a}\right)+\frac{\varphi e_{a}\left(x_{a}\right)}{\gamma^{c}}
$$

where $u_{a}^{I}\left(x_{a}, e_{a}\right)$ is the travel time function for Model-1, which incorporates emission pricing term $e_{a}$. The objective function for Model-1 is similar to the Base-case with the

exception that the second term from equation (7) $\left(\frac{\varphi e_{a}\left(x_{a}\right)}{\gamma^{c}}\right)$ is added to equation (1). The emissions price for each link is updated at the end of every assignment iteration based on the emissions produced as a result of that assignment over the predetermined cap, so that changes in the results of the assignment are reflected in the travel cost faced by each user which like travel time, will vary between assignment iterations. It should be noted that with the revised user cost function the objective of Model-1 is to minimize total system emission (TSE) as opposed to the Base-case where the objective was to minimize total system travel time (TST). In the emission models, an aggregate total emissions or $e_{a}$ is used to determine pricing for each link. While this variable represents a single figure, it is composed of three pollutants calculated within the emissions model. The variable $e_{a}$ represents the total $\mathrm{CO}_{2}$, $\mathrm{VOC}$ and $\mathrm{NO}_{\mathrm{x}}$ produced during each iteration on a highway network link. The final step of the emissions model sums the three pollutants and creates a single emission total from which an emissions charge is calculated.

\section{Model-2: Corridor Based Emission Pricing}

Link based emission pricing provides overall estimates of the user behavior responses to a predefined threshold value. However, pragmatically it may be difficult to implement link based emission pricing. As a revised approach, emission pricing can be applied to corridors (set of contiguous links) instead of individual links. The difficult part is to determine which corridors need to be priced. The threshold value for a corridor can be determined as follows:

$$
\Phi_{b}=\sum\left[\frac{1}{N} \sum_{a=1}^{N}\left(\frac{\phi_{a}}{l_{a}}\right)\right] * l_{a}
$$

where $\phi_{b}$ is the total emissions for corridor $b$, calculated for each link in the base model and $l_{a}$ is the link distance. Similar to equation (7) emission pricing for the corridor $e_{b}$ can be incorporated into the user cost function. However implementation of corridor based emission pricing may be difficult in a demand model. Alternatively, the total pricing for a corridor can be proportionally attributed to each link of the corridor. The emission pricing for a link in the corridor $\left(e_{a}^{I}\right)$ can be obtained by the following equation: 


$$
e_{a}^{I}=\left(\frac{e_{b}}{l_{b}}\right) l_{a}
$$

where $e_{b}$ is the total corridor emission price, $l_{b}$ is the length of the corridor, and $l_{a}$ is the length of link $a$. Similar to the pricing method in Model-1, the corridor emission price is determined at the end of each assignment iteration, based on the amount of emissions produced on the corridor over the cap for each iteration of the assignment model.

\section{Model-3: Variable Demand Emission Pricing}

Both link (Model-1) and corridor based emission pricing (Model-2) provide a good understanding of shifting routes and modes (discussed later in the paper) to minimize total system emission. These models will be very helpful to analyze the reduction of emissions as a result of VEP. However, both Model-1 and Model-2 do not consider the variability of demand because of changes in network conditions as a result of vehicle emission pricing. Alternatively, the users are not elastic to the emission pricing strategy. Demand elasticity can be incorporated into the Base-case by introducing an inverse demand function in the objective function. Modeling variable demand completely changes the objective function. This can be represented as follows:

$$
\text { Minimize } \sum_{a} \int_{0}^{x_{a}}\left(t_{a}\left(x_{a}, e_{a}\right)+\frac{\varphi e_{a}\left(x_{a}\right)}{\gamma^{c}}\right)-\sum_{i j} \int_{0}^{q_{i j}} D_{i j}^{-1}\left(x_{a}, e_{a}\right)
$$

This formulation allows the decision maker to model the elasticity of user behavior. The constraints for the variable demand model remain the same as in the Base-case (see equations 24). The inverse demand function $D_{i j}^{-1}($.$) is associated with O-D pair i-j$. An exponential demand function is then used which is a function of potential demand and least cost user paths to determine the new demand $d_{i j}^{\varphi}\left(x_{i j}\right)$ between O-D pairs is given by

$$
d_{i j}^{\varphi}\left(x_{i j}\right)=\hat{d}_{i j}^{\varphi} \exp \left(-\omega * u_{i j}^{c}\right) \forall i, j, \tau
$$

where $\hat{d}_{i j}^{\varphi}$ is the potential demand between $i-j, u_{i j}^{c}$ is the least cost path between O-D pairs $i-j$ and $\omega$ is a positive constant. In this case the positive constant is .01 and is specified from the literature (17). It represents the typical highway user's response to changes in travel time. The constant is low which means that users react to decreases in travel time, by taking more trips and increases in travel time by taking fewer trips, but do not drastically alter trip rates with changes in time. This new demand is then fed back into the highway assignment model. The users in the $i-j$ O-D pair are now elastic to the cost of travel $\left(u_{i j}^{c}\right)$. Alternatively, as the cost increases the willingness to travel decreases. The emission cap for this case can be at the 
discretion of the decision maker. Link based or corridor based emission pricing can be incorporated into the variable demand model (equation 6, and 8).

\section{Destination and Mode Choice}

The assignment procedure for the Base-case and three models are explained in the earlier section. The demand model should also be sensitive to the destination and mode choice as the network characteristics change. The following section describes steps on how destination choice and mode choice are implemented in the demand model. The utility $U_{i j n}$ of choosing a trip attraction destination $j$ for a trip $n$ produced in zone $i$ is given by:

$$
U_{i j n}=S_{j}+\alpha L_{i j}+\sum \beta^{k} D_{i j}^{k}+\sum \beta^{k} D_{i j}^{k} N_{n}^{k}+\sum \beta^{k} Z_{j}^{k}+C_{j n}
$$

Where, $S_{j}$ is the size variable for destination zone $j, L_{i j}$ is the mode choice logsum between zone pair $i j, D_{i j}^{k}$ represents the various distance terms (linear, log, squared, cubed and square root), $N_{n}^{k}$ represent person, household or production zone characteristics for trip $n$ and is used for creating interaction variables with distance terms, $Z_{j}^{k}$ represents attraction zone characteristics (other than the size term), and $C_{j n}$ is a correction term to compensate for the sampling error in the model estimation (i.e., it represents the difference between the sampling probability and final estimated probability for each alternative). The size variable may consist of several different terms; up to four categories of employment in addition to households were used. Weights $\left(\beta^{k}\right)$ for each term in the size variable were estimated along with all other model parameters as follows, where $E_{j}^{k}$ is employment of type $k$ in zone j:

$$
S_{j}=\log \left(\sum \beta^{k} E_{j}^{k}\right)
$$

The destination choice model provides O-D demand for all trip purposes. A nested logit structure is formulated for mode choice, which is based on generalized utility functions for auto and transit travel. Separate utilities were developed to represent mode choice by trip purpose and time of day. The mode choice utility function is represented as follows:

The complete utility function for mode choice is as follows:

$$
\begin{array}{rl}
U_{m}^{p}=\pi_{m}^{p}+\beta_{1}{ }_{m}^{p} & I V T T_{m}^{p}+\beta_{2}{ }_{m}^{p} T E T_{m}^{p}+\beta_{3}{ }^{p} \times A O C_{m}^{p}+\beta_{4}{ }_{m}^{p} P C_{m}^{p}+\beta_{5 m}^{p} \tau_{m}^{p} \\
& +\beta_{6 m}{ }^{p} W T_{m}^{p}+\beta_{7}{ }_{m}^{p} I W T a 1_{m}^{p}+\beta_{7 m}^{p} I W T b_{m}^{p}+\beta_{8 m}^{p} N O T_{m}^{p} \\
& +{ }_{{ }_{9}{ }_{m}^{p}}^{p} T F_{m}^{p}+\beta_{10}{ }_{m}^{p} D A_{m}^{p}
\end{array}
$$

Where $\pi_{m}^{p}$ is a mode specific constant for mode $m$, and purpose $p ; \beta$ in each term is the mode and attribute specific coefficient; IVTT is the in-vehicle travel time, TET is the terminal 
time, $A O C$ is the auto operating cost, $P C$ is the parking cost; $\tau$ is the toll value, $W T$ is the waiting time, IWTa is the initial waiting time less than 7.5 minutes; IWTb initial waiting time greater than 7.5 minutes; NOT is the number of transfers, TF is the transit fare; and $D A$ is the drive access time. The mode choice model results in splitting O-D trip matrices into 11 travel modes (3 auto modes, and 8 transit modes). Three auto modes refer to Single Occupant Vehicles (SOV), High Occupant Vehicles with 2 occupants (HOV-2), and High Occupant Vehicles with three or more occupants (HOV-3+). Eight transit modes are walk and drive to bus, express bus, rail, and commuter rail.

\section{SOLUTION METHODOLOGY}

Figure 1 shows a flowchart of the solution algorithm for both the Base-case and the three emissions models. The algorithm relies first on inputs commonly found in demand models, which includes the characteristics of the transportation networks (highway and transit), socioeconomic and other inputs needed for the trip generation, destination choice, mode choice and traffic assignment programs. The traffic assignment is solved with a FW algorithm. In the FW when the model has met the convergence criteria, the next model begins by running the first group of programs in the emissions model to setup the emissions inventory derived from the Base-case. The objective of the Base-case is minimization of TST. The algorithm then diverges to run Model-1, Model-2 or Model-3 (with objective of TSE). If the shortest emissions path is selected, the model performs the first iteration of the Model-1/ Model-2 modified assignment with the emissions minimization function. After the first iteration the model checks for convergence then recalculates emissions based on that iteration's assignment results. The iterative procedure between assignment and emissions algorithms continues until the results meet the convergence criteria.

For Model-3, variable demand is calculated based on the least cost path. The variable demand model first skims the Base-case assigned network for congested travel times. The shortest path between all O-D pairs is calculated and used in the inverse demand function to calculate the new demand based on the shortest path. Once the new demand is calculated it is used in the assignment model. The assignment model then iterates between the emissions model and assignment, until the convergence criteria for the assignment program is met. Once the assignment convergence is met the demand is updated as per equation 11 for Model-3. The model iterates between emissions minimization assignment and variable demand until the model converges. The complete model structure is incorporated into the transportation planning software, Cube Voyager (18). The UE assignment algorithm is also modified in Cube Voyager to reflect VEP for all three models. A brief description of the step by step approach is shown in Appendix-A.

<< Figure 1 Here $>>$ 


\section{CASE STUDY}

The proposed framework is applied to Montgomery County in Maryland. Montgomery is the most populous county in the state with a population close to one million, 400,000 households, and employment of 600,000 . The county boundary with the transportation network is presented in Figure 2. The county contains parts of the heavily travelled roadways in the Washington DCBaltimore region (Washington DC is referred to as Washington in the remainder of the paper). The county has an extensive highway network with the Capital Beltway (or Interstate-495), that surrounds Washington, passing through Montgomery County. Interstate-270 interstate forms one leg of an interstate triangle between Washington DC, Baltimore city and Frederick city. The county also contains a portion of route 29, one of the major state routes, which traverses the Washington and Baltimore beltways. In terms of transit, the commuter rail MARC, which travels between Brunswick (North) to Union Station (South), travels completely through Montgomery County. A major metro line (called the Red Line) also travels through the county. In addition, Washington Metropolitan Transit Authority (WMTA) provides bus service and the county has extensive coverage of its own bus system called "RIDE-ON" with very high capacity and frequency.

\section{$<<$ Figure 2 Here $>>$}

There are a total of 4,302 highway links in Montgomery County consisting of all facility types representing a total of 3,630 lane miles. In addition, the network consists of 73 bus lines. A number of transit options are available in the network. Montgomery county has an extensive continuous emission monitoring (CEM) program and the mission is to examine emission reduction strategies. This paper is geared towards this mission to propose a number of emission reduction strategies by using travel demand and emission models. However, the proposed methodology can be extended to other regions.

\section{MODEL APPLICATION}

The Montgomery county study area consists of 223 zones and 49,729 O-D pairs. The data is obtained from the Maryland Statewide Transportation Model developed by The Maryland State Highway Administration. The population, households (by size and five income categories), and employment (four industry categories) are used for trip generation purposes. The destination choice model adequately distributes the trips between O-D pairs as per the formulation presented in Equation (12). Further, the mode choice model splits trips between auto and transit. Additionally, the assignment process provides the shortest user cost paths to the O-D pair and represents user's response. Details of trip generation, destination and mode choice are not 
presented in the paper for brevity and much emphasis is given to highway assignment. The model application section consists of results from the Base-case, and three models.

The summary of results is presented in Table 1 . The first column shows the four cases analyzed. Further, for each case, the emission results from four facility types are presented. For Base-case and for each model the emissions in terms of $\mathrm{NO}_{\mathrm{x}}$, VOC and $\mathrm{CO}_{2}$ are shown in column (3), (4), and (5). In the Base-case, the objective is to minimize travel time through user equilibrium; the effect of the final assignment on total emissions was ignored by the assignment algorithm to satisfy the very purpose of the Base-case which is estimating emissions and not to apply VEP. Emissions are estimated after the traffic assignment stage. The freeways from Basecase resulted in 8.7 million grams of $\mathrm{NO}_{\mathrm{x}}, 1.1$ million grams of VOC, and 1,877 million grams of $\mathrm{CO}_{2}$. Among all facilities in the base case, freeways produce the largest amount of emissions. A total of 1,887 million grams of emissions resulted from the Base-case. A pictorial representation of link-based emission is shown in Figure 3(a). Interstates 495 and 270 are the highest contributors of total emissions. Other areas of concern are along route 29 (lower right corner going north/south) and Connecticut/Georgia avenues (orange links crossing I-495) which are all heavily travelled corridors.

\section{$<$ Figure 3 Here $>>$}

For Model-1, a threshold value or emission cap is determined (please see equation (8)), however the VEP is based on the total amount of emissions that exceed the cap after each iteration of the assignment program, meaning the links to be priced and the amount of the VEP $\left(e_{a}\right)$ changes with the iterative change in link flow $\left(x_{a}\right)$. From the Base-case emission results, the $50^{\text {th }}$ percentile of emissions in grams per mile is determined. The links over the emission cap are subjected to VEP in Model-1. The emission cap is estimated as \$0.0006 per gram (or \$60 per ton) of emissions for travel on links that exceed a predefined emissions cap of 435 thousand grams per mile resulting from the emissions inventory from the Base-case. The assignment algorithm seeks to minimize TSE. Model-1 produces a substantial level of emission reduction resulting in total emissions of 1,433 million grams, and 6.4 million grams $\mathrm{NO}_{\mathrm{x}}, 0.9$ million grams VOC, and 1,426 million grams of $\mathrm{CO}_{2}$ (Table 1). This amounts to a little over $24 \%$ reduction in all emissions. Among the facility types, freeways are still the major contributor (considering the dominate flow pattern over other facility types) but exhibit the largest reduction (44\%) in emissions.

Figure 3(b) presents a map of link emissions in the study area. While Model-1 results in emission reductions, the difficulty in implementing enforcement policy, and the effect it has on non-charged areas outside Montgomery County and the impact on local roads that are able to absorb more emissions due to lower activity levels in the base model, would make this a difficult emission pricing strategy. With new technologies such as GPS tracking and electronic pricing, it is likely that such a strategy could be implemented, but we suggest more a traditional pricing method, by selecting a single heavily emitting corridor as opposed to a single link. 


\section{$<<$ Table 1 Here $>>$}

Model-2 represents the VEP for a single corridor. A corridor is selected where a set of contiguous links over 10 miles produce link based emissions higher than the cap (set at 50\% of emissions per mile for link in the corridor in the Base-case). For the case study, an analysis of the highway network showed that Interstate-270 is the only corridor to meet the criteria. However, for a larger network, there can be multiple corridors, and the model can analyze such an effect. Interstate-270 is a heavily used corridor for commuting between its terminus in Frederick Maryland and Washington DC. Along this corridor are many densely developed areas in Montgomery County. Emissions from this corridor alone account for over $17 \%$ of total vehicle emissions in the Base-case. Model-2 imposes a charge of \$0.0006 per gram of emissions for travel on links that exceed the predefined emissions cap of 1.2 million grams per mile resulting from the emissions inventory from the Base-case. The VEP is only applied to the selected I-270 corridor. Table 1 shows that total emissions for Model-2 are 1,789 million grams with 8.0 million grams $\mathrm{NO}_{\mathrm{x}}, 1.1$ million grams VOC, and 1,780 million grams of $\mathrm{CO}_{2}$. As a result of the corridor pricing strategy, the largest contributor of emissions switches to major arterials. This is largely a result of users selecting alternative routes that are within Montgomery County but still result in lower travel time. While Model-2 leads to an overall reduction in emissions of over 5\%, it results in increased emissions for all other facility types due to excess use which produces a higher volume of trips and a greater number of congested lane miles increasing emissions on major arterials by $18 \%$, minor arterials $21 \%$ and other roads by $6.5 \%$. Figure 3(c) shows the results of Model-2 on emissions in the study area. The results show there is a substantial improvement of generally over 50\% reduction in emissions along the corridor. The figure also shows the impact of VEP on a single corridor. Neighboring links become saturated with traffic and emissions increase. However, these links are generally able to absorb enough extra volume and emissions that TSE is reduced.

Model-3 represents variable demand conditions, modeling the elastic nature of travelers' behavior to the given network conditions. When VEP strategy is employed in the variable demand model a number of users may first decide whether or not to make a trip subject to imposed user costs. The "willingness to travel" was not analyzed in the earlier two models. For the variable demand model, in equation (11) the value of $\omega$ is 0.01 representing the elasticity of users response to travel cost (9) . The total emissions from Model-3 resulted in 1,717 million grams with 7.9 million grams $\mathrm{NO}_{\mathrm{x}}, 1.0$ million grams VOC, and 1,708 million grams of $\mathrm{CO}_{2}$. For Model-3, a reduction in all pollutants for all facility types was achieved. The results show a reduction of $9 \%$ in total emissions, falling between the Model-1 and Model-2 results. Users' response to levels of congestion and VEP on the 270 corridor helped to improve emissions by reducing the number of vehicle trips taken within the county.

Figure 3(d) shows the change in link level emissions produced by the combination of corridor VEP and variable demand. Much of the improvement in emission results from VEP and reductions in demand for travel in the county due to the added cost of travel along the 270 
corridor. Travel costs also increase on arterials and local roads as the cost in time to divert around the corridor and in fuel expense reduces demand for travel on many roads. Some local streets show an increase in emissions as the cost of travel is comparatively low and does not increase to a level high enough to reduce total demand for trips. Emissions on the VEP corridor show reductions ranging from $25 \%$ to $50 \%$ for all links.

\section{SYNTHESIS OF MODEL RESULTS}

Results for the Base-case and three models are presented in Table 2. Each model output is further categorized by facility type. The first column in Table 2 provide the total system travel time (TST), followed by the total system emissions (TSE) shown in columns (3) and (4). The table also shows the vehicle miles travelled (VMT), average speed, number of congested lane miles (lengths of road with a volume to capacity ratio of over 0.75 ), and the number of links that are charged (exceed the predetermined cap) from each model.

In the Base-case TST is 154,453 hours and total VMT is 4,199,854 hours, which results in an average speed of 27 miles per hour. Without any emissions reduction strategies total system emissions for the Base-case are at the highest level compared to the three models. This is in part due to amount of traffic volume on the highways which results in a total of 376 congested lane miles with the majority of those miles on freeways and major arterials.

Model-1 shows a 9.6\% improvement in TST when VEP is applied to each link that exceeds the predetermined emissions cap; which is calculated between iterations of the assignment algorithm. The reductions in freeway travel time (57\%) and increase in average speed (from 38 to $49 \mathrm{mph}$ ) is greatest for freeways, with a modest improvement in major arterials (32\% decrease in TST and one mph increase in speed). However there is an increase on minor arterials for TST (59\%) and reduction in average speed (from 23 to $18 \mathrm{mph}$ ) and for other roads (38\% increase in TST and four mph decrease in speed). This result is mirrored in the level of emissions (29\% and 20\% respectively) and number of congested lane miles (124\% and 269\%). Freeways and arterials show significant improvements in reducing both emissions and congestion while minor arterials and other roads result in an opposite trend. There are two phenomena acting in Model-1 to produce the results. First, the study area is only a small part of a larger transportation network that consists of links outside Montgomery County. As a result, users have a variety of alternative routes to select from when making a trip. When all links are potentially subjected to VEP, it is more cost effective for some users (with a low VOT) to select a route that is outside of the study area, effectively outside the potential VEP area. This produces an overall decrease in VMT and helps reduce system emissions and congestion. At the same time, by setting a target emissions level (cap) dependent on the 50th percentile of emissions per mile, some less travelled roads gain emissions capacity while other congested roads are significantly over capacity. Since the VEP is a measure of emissions over capacity, many of the 
lower facility types such as minor arterials, collectors and other roads become feasible noncharged routes for users with a lower VOT; in other words, those that can spend the time to go around the charged links. As a result of this, emissions levels, travel time, VMT and congestion all significantly increase on these out of the way but cheaper routes.

Model-2 demonstrates that the corridor VEP model achieves a lower reduction in emissions (5\% compared to 24\% in Model-1) but only initiates a VEP strategy on 162 links compared to the 1,405 links required in Model-1. Model-2 results in higher average freeway speeds than the Base-case, providing a 39\% reduction in freeway congested lane miles. The model also shows increases in TST (5\%) and an increase over the Base-case in total congested lane miles (20\%). This occurs, much like in Model-1, because users find it cost effective to avoid travel on the VEP corridor and unlike in Model-1 there is no additional emissions charge for users to select a route that avoids the corridor. Because of the availability of cost effective routes within Montgomery County users chose major and minor arterials.

$<<$ Table 2 Here $>>$

Model-3 measures the relationship between emission reduction goals and user response by implementing a variable demand model along with the corridor VEP strategy. The results of this combined model show improvement for all indicators and all facility types (except congested lane miles for minor arterials increases 7\%). The improvements occur in part because of the corridor VEP implemented in this model but also because the variable demand component of model results in a reduction in the total number of vehicle trips both beginning and ending in O-D pairs within the study area. In total, there is a reduction in highway travel demand of over 63,000 vehicle trips for all O-D pairs in Montgomery County. This figure represents the number of vehicle trips that are not assigned to the highway network due to user elasticity in trip making decisions as a direct result of increases in the cost of travel from both congested travel time and VEP. The results show that using a variable demand function, $16 \%$ of the 396,500 highway trips that would otherwise occur in the county either do not occur at all or are taken using other modes.

This reduction in vehicle trips leads to an overall average system speed of $28 \mathrm{mph}$, which is higher than the Base-case and Models 1 and 2. The results also show improvement in total congested lane miles which shows a $22 \%$ improvement over the Base-case. In a single instance, on minor arterials, congested lane miles increased. This model provides a good estimate on how users might react with knowledge about road conditions and travel cost is known.

\section{$<<$ Figure 4 Here $>>$}

To test for convergence the gap (see Appendix-A, equation A.4) between assignment iterations in the case of the Base-case and models 1 through 2 and assignment iterations and loop iterations for model 3, was measured. Gap is a function of change in assigned link volumes and cost between iterations, so that as gap decreases the assignment gets closer to convergence which 
indicates that a change in travel cost for a link does not produce a significant change in the entire network. For this paper the convergence criteria was set at a gap of 0.002 for the iterative assignment and 0.005 for the variable demand iteration. Figure 4 shows the iteration results in terms of the gap for fifty model iterations. In all cases the models reached the convergence criteria in less than 26 iterations. The three models had computational times per iteration of 12 minutes for Model-1, 8 minutes for Model-2 and 40 minutes for Model-3. The assignment iteration time varies as result of the emissions model feedback into the assignment algorithm. Model-1 has a longer processing time because more links require emissions calculations. Model3's computation time was longer because each variable demand iteration has a nested traffic assignment program that also had to iterate and converge. The Base-case and all three models were run in Cube Voyager using multi-core distributed processing in a Windows Server 2008. However the processing times may vary as the computer configuration is altered.

\section{CONCLUSION}

This paper presents VEP as a tool for emission reduction strategies. A joint travel demand and emission model incorporates the VEP strategies proposed in the paper. The demand model incorporates individual travel behavior in determining the choice of destination, mode and route in response to VEP strategies set by the decision maker. The emissions model, MOVES, developed by the EPA is integrated with the demand model for estimation of link based pollutants. Developing such models is complex and involves two major hurdles. First, the difficulty lies in obtaining a certain emission level to model individual driver responses to examine how the targets are achieved. Second, the complexity involved in developing multiple strategies in real world case studies for assisting federal, state and local agencies (or decision makers) to achieve emission reduction objectives. The proposed model addresses both hurdles. First, a robust model formulation is presented incorporating differential VEP strategies. Second, the model is applied to a multimodal transportation network in Montgomery County in Maryland, where the roadway infrastructure connects to the Washington-Baltimore region.

A Base-case depicting existing conditions and three models are proposed. The existing conditions are depicted in the Base-case, and emission level is estimated after the traffic assignment. The Base-case resulted in high levels of emissions and led to the development of three models. Model-1 represents a link based VEP suggesting links exceeding a predefined emission level will be penalized. Model-2 demonstrates a practical way of VEP implementation at a corridor level (set of contiguous links) as opposed to link level. Model-3 is a more advanced way of analyzing VEP through variable demand, incorporating the willingness to travel component as opposed to the deterministic nature of traffic assignment models. It should be noted that the emission cap is predetermined by the decision maker and the assignment algorithm defines the links in the network to be subjected to VEP in a joint travel demand and emission 
model. While the Base-case illustrates the existing emission levels, three proposed models provide insightful results in emission reduction.

The proposed model has several dimensions of significant impact and contribution to practice. First, development of a functional joint travel demand and emission model to incorporate VEP strategies. Second, procedural development of three models that incorporate decision maker's strategies in emission minimization to examine user's response. Third, application of the proposed methodology successfully to a real world case study to present emission estimates for different policy levels.

This paper provides a theoretically robust framework for emissions reduction strategies and further examines user behavior using a joint travel demand and emission model. The results show that through the implementation of VEP, critical emission reduction targets are achievable. While some strategies such as charging all links that exceed a predetermined cap may not be feasible; others that implement VEP along a single corridor show improvements in emissions with fewer resource requirements. The tools developed in this paper offer planners and decision makers a method to test the implications of various emissions policy objectives which is particularly important in the current era of environmental impact awareness. This research can be extended to incorporate uncertainty in travel demand and consequences to emission modeling.

\section{ACKNOWLEDGEMENT}

The authors are thankful to the Maryland State Highway Administration (SHA) for their continued support in the development of Maryland Statewide Transportation Model (MSTM). The tremendous effort by the staff at Parsons Brinkerhoff in the data collection and model development is also greatly acknowledged. The evolution of MSTM is a result of continued research for the last four years at the National Center for Smart Growth Research and Education, at University of Maryland. The research on emission reduction strategies are aimed at development of a real world model that can be used by the state, county and local agencies. The opinions and viewpoints expressed are entirely those of the authors, and do not necessarily represent policies and programs of the agencies mentioned in the paper.

\section{REFERENCE}

1. Greene, D. L. (2011) What is greener than a VMT tax? The case for an indexed energy user fee to finance us surface transportation, Transportation Research Part D: Transport and Environment 16, 451-458.

2. Sharma, S., and Mishra, S. (2011) Optimal emission pricing models for containing carbon footprints due to vehicular pollution in a city network, in Transportation Research Board 90th Annual Meeting.

3. Sugawara, S., and Niemeier, D. (2002) How Much Can Vehicle Emissions Be Reduced?: Exploratory Analysis of an Upper Boundary Using an Emissions-Optimized Trip Assignment, Transportation Research Record: Journal of the Transportation Research Board 1815, 29-37. 
4. Sharma, S., and Mathew, T. V. (2011) Multiobjective network design for emission and travel-time trade-off for a sustainable large urban transportation network, Environment and Planning B: Planning and Design 38, 520-538.

5. Sheffi, Y. (1984) Urban transportation networks: Equilibrium analysis with mathematical programming methods. Prentice-Hall Englewood Cliffs, NJ.

6. Barth, M., An, F., Norbeck, J., and Ross, M. (1996) Modal Emissions Modeling: A Physical Approach, Transportation Research Record: Journal of the Transportation Research Board 1520, 81-88.

7. Nagurney, A. (2000) Congested urban transportation networks and emission paradoxes, Transportation Research Part D: Transport and Environment 5, 145-151.

8. Hearn, D. W., and Yildirim, M. B. (2001) A toll pricing framework for traffic assignment problems with elastic demand. Kluwer Academic Publishers, Dordrecht, Netherlands.

9. Yildirim, M. B., and Hearn, D. W. (2005) A first best toll pricing framework for variable demand traffic assignment problems, Transportation Research Part B: Methodological 39, 659-678.

10. Arnott, R., Small, K., and Economics, B. C. D. of. (1994) The economics of traffic congestion, American Scientist 82, 446-446.

11. Button, K. J., and Verhoef, E. T. (1998) Road pricing, traffic congestion and the environment: Issues of efficiency and social feasibility. Edward Elgar Publishing.

12. Yin, Y., and Lawphongpanich, S. (2006) Internalizing emission externality on road networks, Transportation Research Part D: Transport and Environment 11, 292-301.

13. Benedek, C. M., and Rilett, L. R. (1998) Equitable traffic assignment with environmental cost functions, Journal of transportation engineering 124, 16.

14. Washbrook, K., Haider, W., and Jaccard, M. (2006) Estimating commuter mode choice: A discrete choice analysis of the impact of road pricing and parking charges, Transportation 33, 621-639.

15. Johansson-Stenman, O., and Sterner, T. (1997) What is the scope for environmental road pricing?, Button, KJ and ET Verhoef (eds.), Road Pricing. Traffic Congestion and the Environment: Issues of efficiency and social feasibility.

16. Sheffi, Y. (1985) Urban transportation networks. Prentice-Hall.

17. Ukkusuri, S. V., and Patil, G. (2009) Multi-period transportation network design under demand uncertainty, Transportation Research Part B: Methodological 43, 625-642.

18. Citilabs. (2011) Cube Voyager. 
Appendix-A: Joint Travel Demand and Emissions Model Algorithm Summary

\section{Step 0: Initialization.}

Calculate initial demand $\left(q_{i j}^{c(0)}\right)$ and feasible flow pattern $\left(f_{i j}^{c(0)}\right)$, based of free-flow travel time. Set $(n)=0$.

Step 1a: Update.

$$
\text { Set } t_{a}\left(x_{a}\right)=t_{a}\left(1+\alpha_{a}\left(\frac{x_{a}}{c_{a}}\right)\right)^{\beta_{a}} \forall a \text {; }
$$

Step 1b: Update with variable demand.

Update demand with inverse demand function

$$
d_{i j}^{\varphi}\left(\sigma_{i j}\right)=d_{i j}^{\tau} \exp \left(-\omega * u_{i j}^{c(m)}\right) \quad \forall_{i j, \tau}
$$

where $u_{i j}^{c}$ is the least cost path between O-D pairs $\mathrm{i}$ and $\mathrm{j}$ and $\omega$ is a positive constant.

\section{Step 2: Direction Finding.}

Find the shortest path

$$
u_{i j}^{c(n)}=t_{a}\left(x_{a}\right)+\frac{\tau_{a}\left(x_{a}\right)}{\gamma^{c}}
$$

Perform all-or-nothing assignment based on updated travel times and obtain auxiliary flows $f_{i j}^{c(m)}$

\section{Step 3: Move Size.}

Line search for optimal step size, solving for $a$ :

$$
\text { Minimize } \sum_{a} \int_{0}^{x_{a}}\left(t_{a}\left(x_{a}, e_{a}\right)+\frac{\tau_{a}\left(x_{a}\right)}{\gamma^{c}}+\frac{\varphi e_{a}\left(x_{a}\right)}{\gamma^{c}}\right)
$$

\section{Step 4: Flow Update with emissions charge.}

Find $f_{a}^{c t(m)}, f_{a}^{c e(m)}, f_{a}^{c n(m)}$ with:

$$
u_{i j}^{c(n)}\left(x_{a}, e_{a}\right)=t_{a}\left(x_{a}, e_{a}\right)+\frac{\tau_{a}\left(x_{a}\right)}{\gamma^{c}}+\frac{\varphi e_{a}\left(x_{a}\right)}{\gamma^{c}}
$$

Step 5: Assignment convergence criterion.

$$
K \leq \frac{A b s\left[\sum_{a \in A}\left(f_{a}^{(n)} * t_{a a}^{c(n)}\right)-\sum_{a \in A}\left(f_{a}^{(n-1)} * \delta_{a}^{c(n-1)}\right)\right]}{\sum_{a \in A}\left(f_{a}^{(n-1)} * \delta_{a}^{c(n-1)}\right)}
$$

where $\mathrm{K}$ is a dimensionless convergence criterion

For Model-1 and Model-2 step 1(b) is skipped. For Model-3, all the steps are executed. If inequality holds, terminate assignment and go to step 1a. Otherwise, set $n=n+1$ and go to step 1. 
List of Tables

\begin{tabular}{ll}
\hline Table Number & Title \\
\hline 1 & Emissions by Pollutant and Facility Type \\
2 & Summary of Results \\
\hline
\end{tabular}

\section{List of Figures}

\begin{tabular}{ll}
\hline Figure Number & Title \\
\hline 1 & Solution Methodology \\
2 & Montgomery County Transportation Network \\
3 & Emission Results for Base-case and three models \\
4 & Convergence Results for All Models \\
\hline
\end{tabular}


TABLE 1 Emissions by Pollutant and Facility Type

\begin{tabular}{|c|c|c|c|c|c|c|c|c|c|}
\hline \multirow[b]{2}{*}{$\begin{array}{c}\text { Model } \\
(1)\end{array}$} & \multirow[b]{2}{*}{$\begin{array}{c}\text { Facility Type } \\
\text { (2) }\end{array}$} & \multirow{2}{*}{$\begin{array}{c}\text { NOX } \\
\text { (gm) } \\
(3) \\
\end{array}$} & \multirow{2}{*}{$\begin{array}{c}\text { VOC } \\
\text { (gm) } \\
(4)\end{array}$} & \multirow{2}{*}{$\begin{array}{c}\text { CO2EQ } \\
\text { (gm) } \\
(5) \\
\end{array}$} & \multirow[b]{2}{*}{$\begin{array}{c}\text { Total } \\
(6) \\
\end{array}$} & \multicolumn{4}{|c|}{ Percent Change } \\
\hline & & & & & & $\begin{array}{c}\text { NOX } \\
\text { (7) }\end{array}$ & $\begin{array}{l}\text { VOC } \\
(8)\end{array}$ & $\begin{array}{c}\text { CO2EQ } \\
\text { (9) }\end{array}$ & $\begin{array}{c}\text { Total } \\
\text { (10) }\end{array}$ \\
\hline \multirow{5}{*}{ Base-Case } & Freeway & $4,619,807$ & 401,952 & $851,912,900$ & $856,934,658$ & & & & \\
\hline & Major Arterial & $2,637,581$ & 419,295 & $604,646,167$ & $607,703,044$ & & & & \\
\hline & Minor Arterial & 515,946 & 107,596 & $147,206,819$ & $147,830,362$ & & & & \\
\hline & Other* & 971,794 & 204,015 & $273,611,629$ & $274,787,438$ & & & & \\
\hline & SUM & $8,745,128$ & $1,132,858$ & $1,877,377,516$ & $1,887,255,502$ & & & & \\
\hline \multirow{5}{*}{ Model-1 } & Freeway & $2,591,969$ & 226,547 & $479,541,402$ & $482,359,917$ & $-43.89 \%$ & $-43.64 \%$ & $-43.71 \%$ & $-43.71 \%$ \\
\hline & Major Arterial & $1,870,555$ & 297,512 & $429,569,086$ & $431,737,153$ & $-29.08 \%$ & $-29.04 \%$ & $-28.96 \%$ & $-28.96 \%$ \\
\hline & Minor Arterial & 664,779 & 138,604 & $189,342,464$ & $190,145,847$ & $28.85 \%$ & $28.82 \%$ & $28.62 \%$ & $28.62 \%$ \\
\hline & Other & $1,229,364$ & 252,932 & $327,356,255$ & $328,838,551$ & $26.50 \%$ & $23.98 \%$ & $19.64 \%$ & $19.67 \%$ \\
\hline & SUM & $6,356,667$ & 915,594 & $1,425,809,207$ & $1,433,081,468$ & $-27.31 \%$ & $-19.18 \%$ & $-24.05 \%$ & $-24.07 \%$ \\
\hline \multirow{5}{*}{ Model-2 } & Freeway & $3,218,227$ & 283,255 & $597,291,224$ & $600,792,706$ & $-30.34 \%$ & $-29.53 \%$ & $-29.89 \%$ & $-29.89 \%$ \\
\hline & Major Arterial & $3,127,116$ & 494,298 & $713,126,346$ & $716,747,759$ & $18.56 \%$ & $17.89 \%$ & $17.94 \%$ & $17.94 \%$ \\
\hline & Minor Arterial & 618,976 & 129,245 & $177,964,400$ & $178,712,621$ & $19.97 \%$ & $20.12 \%$ & $20.89 \%$ & $20.89 \%$ \\
\hline & Other & $1,041,492$ & 218,020 & $291,343,114$ & $292,602,626$ & $7.17 \%$ & $6.86 \%$ & $6.48 \%$ & $6.48 \%$ \\
\hline & SUM & $8,005,810$ & $1,124,817$ & $1,779,725,085$ & $1,788,855,711$ & $-8.45 \%$ & $-0.71 \%$ & $-5.20 \%$ & $-5.21 \%$ \\
\hline \multirow{5}{*}{ Model-3 } & Freeway & $3,841,938$ & 335,182 & $709,149,495$ & $713,326,615$ & $-16.84 \%$ & $-16.61 \%$ & $-16.76 \%$ & $-16.76 \%$ \\
\hline & Major Arterial & $2,584,698$ & 410,782 & $591,779,339$ & $594,774,819$ & $-2.01 \%$ & $-2.03 \%$ & $-2.13 \%$ & $-2.13 \%$ \\
\hline & Minor Arterial & 493,755 & 102,901 & $140,536,452$ & $141,133,108$ & $-4.30 \%$ & $-4.36 \%$ & $-4.53 \%$ & $-4.53 \%$ \\
\hline & Other & 942,737 & 198,892 & $266,170,415$ & $267,312,044$ & $-2.99 \%$ & $-2.51 \%$ & $-2.72 \%$ & $-2.72 \%$ \\
\hline & SUM & $7,863,129$ & $1,047,757$ & $1,707,635,701$ & $1,716,546,587$ & $-10.09 \%$ & $-7.51 \%$ & $-9.04 \%$ & $-9.05 \%$ \\
\hline
\end{tabular}

* "Other" represents collector and local facility types. 
TABLE 2 Summary of Results

\begin{tabular}{|c|c|c|c|c|c|c|c|c|c|c|c|}
\hline \multirow[b]{2}{*}{$\begin{array}{c}\text { Model } \\
\text { (1) }\end{array}$} & \multirow[b]{2}{*}{$\begin{array}{c}\text { Facility Type } \\
\text { (2) }\end{array}$} & \multirow[b]{2}{*}{$\begin{array}{c}\text { TST } \\
\text { (hrs) } \\
(3) \\
\end{array}$} & \multirow[b]{2}{*}{$\begin{array}{c}\text { TSE } \\
\text { (gm) } \\
(4) \\
\end{array}$} & \multirow[b]{2}{*}{$\begin{array}{l}\text { VMT } \\
\text { (5) }\end{array}$} & \multirow[b]{2}{*}{$\begin{array}{c}\text { Averge Speed } \\
\text { (MPH) } \\
\text { (6) }\end{array}$} & \multirow[b]{2}{*}{$\begin{array}{c}\text { Congested } \\
\text { Lane Miles } \\
\text { (7) } \\
\end{array}$} & \multirow[b]{2}{*}{$\begin{array}{l}\text { Charged } \\
\text { Links } \\
\text { (8) }\end{array}$} & \multicolumn{4}{|c|}{ Percent Change } \\
\hline & & & & & & & & $\begin{array}{l}\text { TST } \\
(9) \\
\end{array}$ & $\begin{array}{l}\text { TSE } \\
(10) \\
\end{array}$ & $\begin{array}{l}\text { VMT } \\
\text { (11) }\end{array}$ & $\begin{array}{c}\text { Congested } \\
\text { Lane Miles } \\
\text { (12) } \\
\end{array}$ \\
\hline \multirow{5}{*}{ Base-Case } & Freeway & 41,319 & $856,934,658$ & $1,550,307$ & 38 & 197 & N/A & & & & \\
\hline & Major Arterial & 55,434 & $607,703,044$ & $1,392,557$ & 25 & 118 & N/A & & & & \\
\hline & Minor Arterial & 21,233 & $147,830,362$ & 484,132 & 23 & 30 & N/A & & & & \\
\hline & Other* & 36,467 & $274,787,438$ & 772,858 & 21 & 30 & $\mathrm{~N} / \mathrm{A}$ & & & & \\
\hline & SUM & 154,453 & $1,887,255,502$ & $4,199,854$ & 27 & 376 & $\mathrm{~N} / \mathrm{A}$ & & & & \\
\hline \multirow{5}{*}{ Model-1 } & Freeway & 17,890 & $482,359,917$ & 883,954 & 49 & 13 & 191 & $-56.70 \%$ & $-43.71 \%$ & $-42.98 \%$ & $-93.34 \%$ \\
\hline & Major Arterial & 37,732 & $431,737,154$ & 995,796 & 26 & 59 & 486 & $-31.93 \%$ & $-28.96 \%$ & $-28.49 \%$ & $-50.02 \%$ \\
\hline & Minor Arterial & 33,687 & $190,145,847$ & 619,526 & 18 & 66 & 265 & $58.65 \%$ & $28.62 \%$ & $27.97 \%$ & $124.16 \%$ \\
\hline & Other & 50,322 & $328,838,550$ & 837,824 & 17 & 112 & 463 & $37.99 \%$ & $19.67 \%$ & $8.41 \%$ & $268.58 \%$ \\
\hline & SUM & 139,631 & $1,433,081,468$ & $3,337,100$ & 24 & 250 & 1,405 & $-9.60 \%$ & $-24.07 \%$ & $-20.54 \%$ & $-33.34 \%$ \\
\hline \multirow{5}{*}{ Model-2 } & Freeway & 26,417 & $600,792,706$ & $1,108,076$ & 42 & 121 & 162 & $-36.07 \%$ & $-29.89 \%$ & $-28.53 \%$ & $-38.66 \%$ \\
\hline & Major Arterial & 69,186 & $716,747,759$ & $1,624,195$ & 23 & 213 & 0 & $24.81 \%$ & $17.94 \%$ & $16.63 \%$ & $80.00 \%$ \\
\hline & Minor Arterial & 28,206 & $178,712,620$ & 597,903 & 21 & 68 & 0 & $32.84 \%$ & $20.89 \%$ & $23.50 \%$ & $130.21 \%$ \\
\hline & Other & 38,819 & $292,602,626$ & 816,928 & 21 & 49 & 0 & $6.45 \%$ & $6.48 \%$ & $5.70 \%$ & $61.30 \%$ \\
\hline & SUM & 162,629 & $1,788,855,711$ & $4,147,101$ & 26 & 451 & 162 & $5.29 \%$ & $-5.21 \%$ & $-1.26 \%$ & $20.12 \%$ \\
\hline \multirow{5}{*}{ Model-3 } & Freeway & 29,204 & $713,326,615$ & $1,293,499$ & 44 & 115 & 162 & $-29.32 \%$ & $-16.76 \%$ & $-16.56 \%$ & $-41.93 \%$ \\
\hline & Major Arterial & 53,838 & $594,774,819$ & $1,356,430$ & 25 & 117 & 0 & $-2.88 \%$ & $-2.13 \%$ & $-2.59 \%$ & $-1.01 \%$ \\
\hline & Minor Arterial & 20,008 & $141,133,108$ & 459,305 & 23 & 32 & 0 & $-5.77 \%$ & $-4.53 \%$ & $-5.13 \%$ & $6.69 \%$ \\
\hline & Other & 33,356 & $267,312,044$ & 752,093 & 23 & 28 & 0 & $-8.53 \%$ & $-2.72 \%$ & $-2.69 \%$ & $-7.11 \%$ \\
\hline & SUM & 136,406 & $1,716,546,587$ & $3,861,327$ & 28 & 292 & 162 & $-11.68 \%$ & $-9.05 \%$ & $-8.06 \%$ & $-22.39 \%$ \\
\hline
\end{tabular}

* "Other" represents collector and local facility types. 


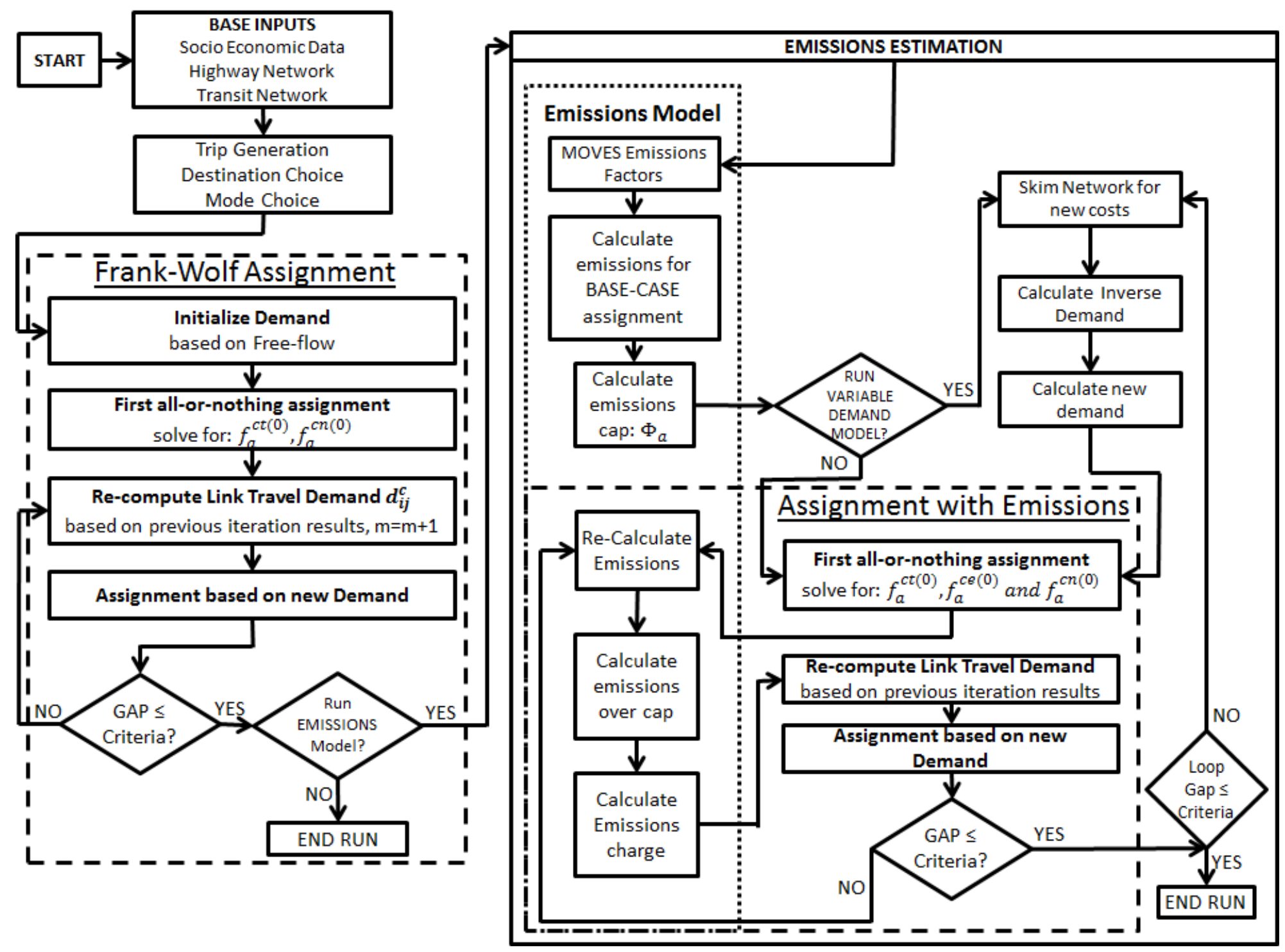

FIGURE 1 Solution Methodology 


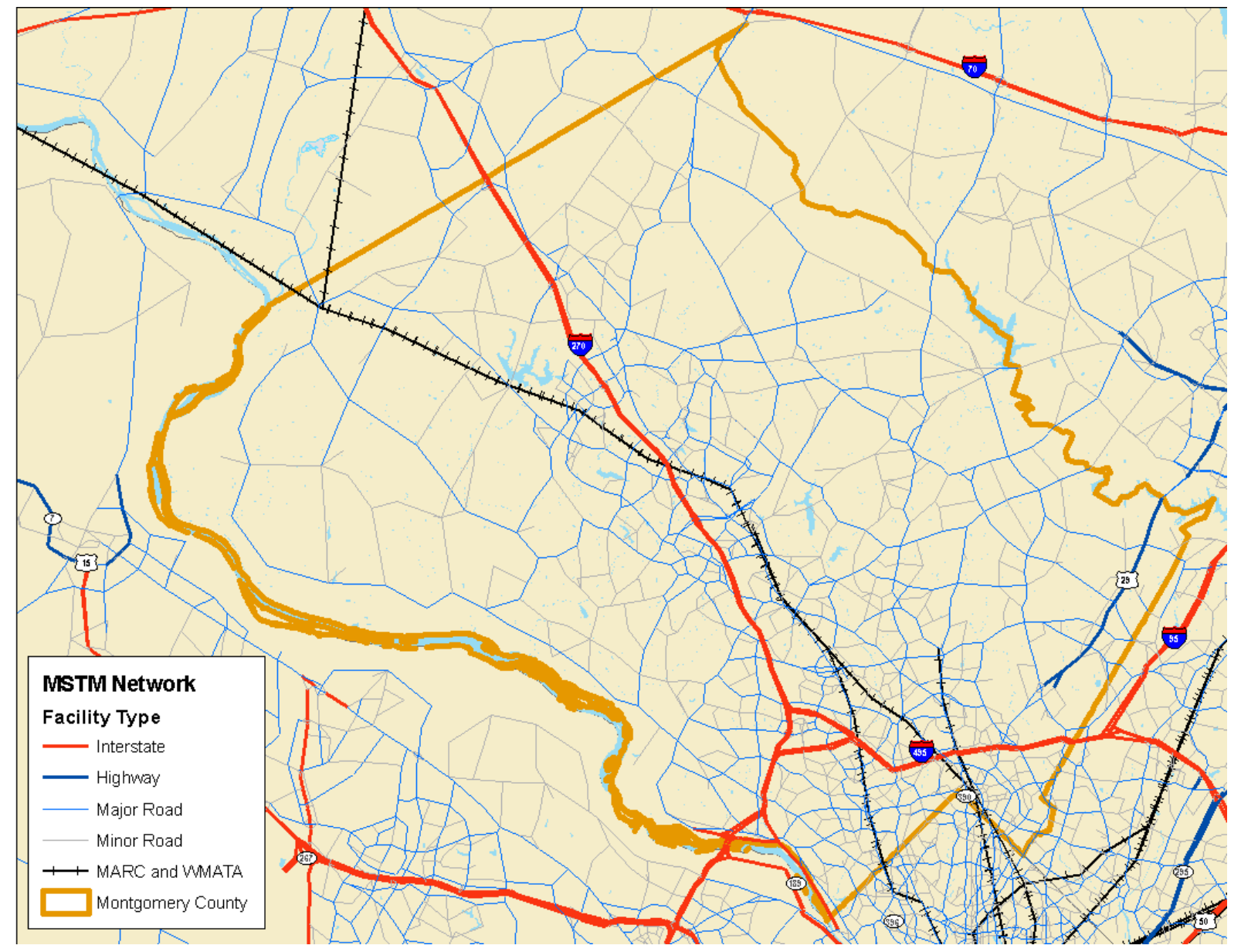

FIGURE 2 Montgomery County Transportation Network 


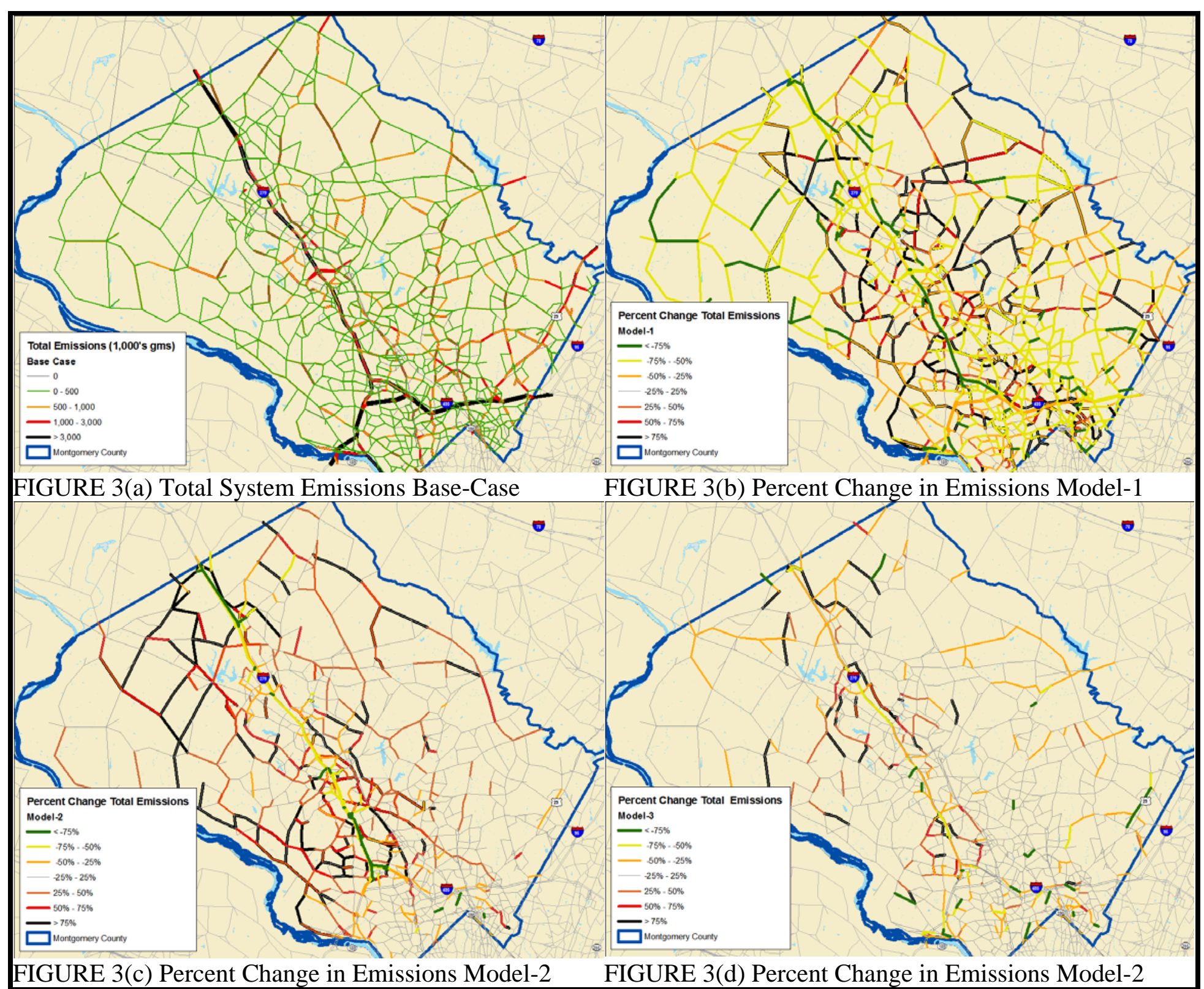

FIGURE 3 Emission Results for Base-case and Three Models 


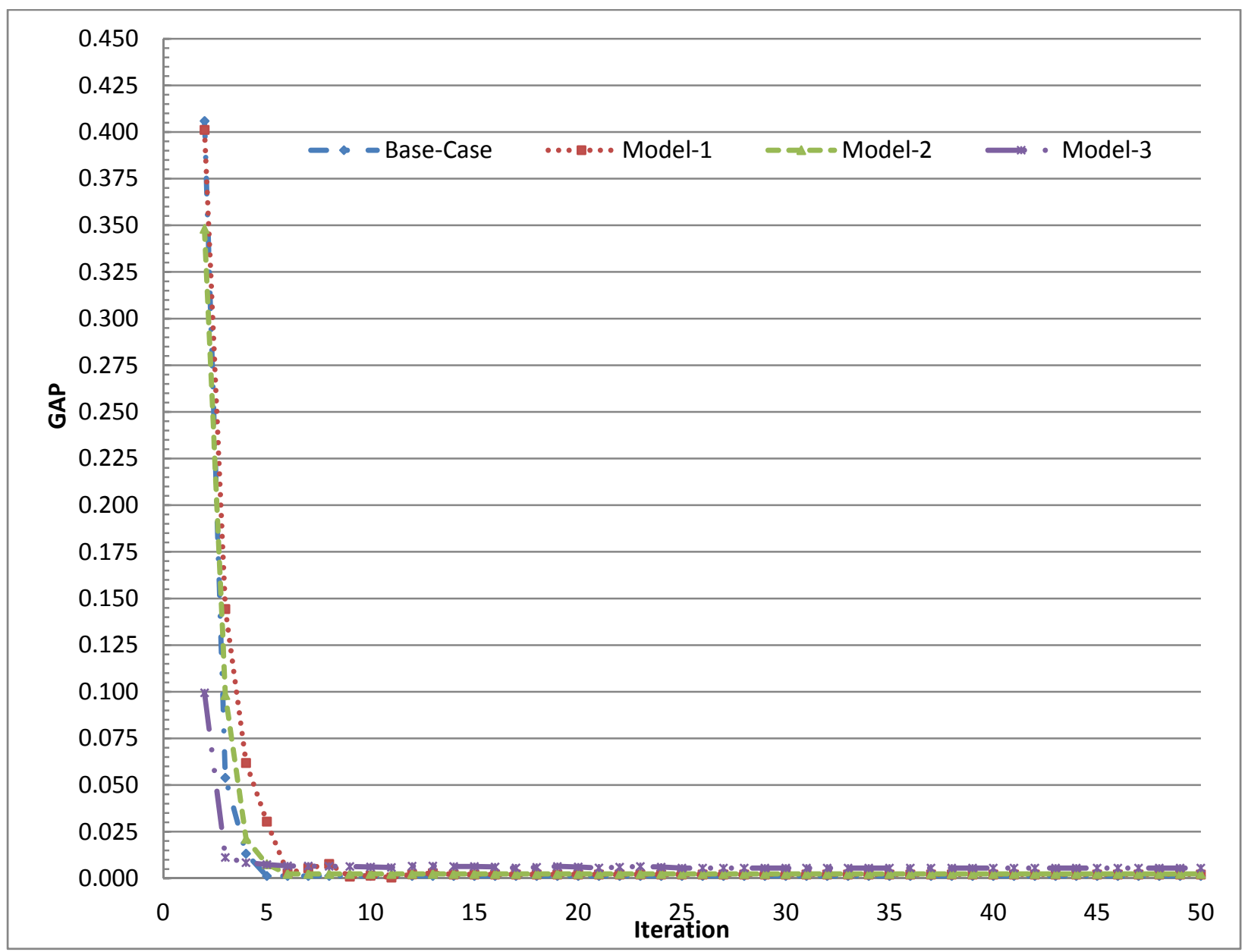

FIGURE 4 Convergence Results for All Models 